\title{
Article
}

Arq Neuropsiquiatr 2011;69(5):760-765

\section{Electronystagmography findings in spinocerebellar ataxia type 3 (SCA3) and type 2 (SCA2)}

\author{
Bianca Simone Zeigelboim ${ }^{1,2}$, Hélio A.G. Teive², Rosane Sampaio 1,2, \\ Ari Leon Jurkiewicz' ${ }^{1}$ Paulo B.N. Liberalesso'
}

\begin{abstract}
Objective: To describe the alterations observed in electronystagmography (ENG) of patients with spinocerebellar ataxia (SCA) types 2 and 3. Method: Sixteen patients were studied and the following procedures were carried out: anamnesis, otorhinolaryngological and vestibular evaluations. Results: The clinical findings in the entire group of patients were: gait disturbances (93.75\%), dysarthria (43.75\%), headache (43.75\%), dizziness $(37.50 \%)$ and dysphagia (37.50\%). In the vestibular exam, the rotatory (62.50\%) and caloric (75\%) tests were among those which presented the largest indexes of abnormalities; the presence of alterations in the exams was $87.50 \%$, with a predominance of central vestibular disorders in $68.75 \%$ of the exams. Conclusion: Vestibular exams could be an auxiliary tool to investigate SCAs, besides a precise clinical approach and, particularly, molecular genetic tests. Key words: spinocerebellar ataxias, vestibular dysfunction, electronystagmography.
\end{abstract}

Eletronistagmografia em ataxia espinocerebelar do tipo 3 (SCA3) e do tipo 2 (SCA2)

\section{RESUMO}

Objetivo: Verificar as alterações do exame de eletronistagmografia (ENG) em pacientes com ataxia espinocerebelar (AEC) tipos 2 e 3. Método: 16 pacientes foram estudados, com a utilização dos seguintes procedimentos: anamnese, avaliação otorrinolaringológica e avaliação vestibular. Resultados: As principais queixas encontradas na anamnese foram, desequilíbrio na marcha (93,75\%), dificuldades da fala $(43,75 \%)$, cefaleia (43,75\%), tontura $(37,50 \%)$ e disfagia (37,50\%). No exame vestibular, o teste rotatório e o teste calórico apresentaram os maiores índices de anormalidades, respectivamente, $62,50 \%$ e $75 \%$, com a predominância de distúrbio vestibular do tipo central em $68,75 \%$ dos casos. Conclusão: O exame vestibular pode ser um exame auxiliar na investigação das AECs, junto com a avaliação clínica precisa e, particularmente, com os testes de genética molecular.

Palavras-Chave: ataxia espinocerebelar, disfunção vestibular, eletronistagmografia.

Autosomal dominant cerebellar ataxias, currently denominated spinocerebellar ataxias (SCAs), represent a heterogeneous group of neurodegenerative disorders primarily affecting the cerebellum and its afferent and efferent connections, particularly brainstem, and spinal cord ${ }^{1-4}$. Classical clinical findings of SCAs are progressive gait and limb cerebellar ataxia, associated with nystagmus, dysarthria, and ophthalmoparesis. SCAs may also in- clude varying degree of additional signs from other parts of the nervous system: other movement disorders (dystonia, parkinsonism, tremor, and myoclonus), spasticity, peripheral neuropathy, cognitive impairment, epilepsy, autonomic disturbances, optic atrophy, and retinopathy. Neuroimaging techniques, particularly MRI, have been useful to demonstrate cerebellar, brainstem, and occasionally whole brain atrophy in some forms of SCAs $s^{2-5}$.
National Council of Scientific and Technological Development (CNPQ)

Received 13 February 2011 Received in final form 6 May 2011 Accepted 13 May 2011
'Otoneurology Unit, MSc and PhD Program in Communication Disorders, Tuiuti University of Paraná, Curitiba PR, Brazil ${ }^{2}$ Neurology Service, Department of Clinical Medical, Clinical Hospital, Federal University of Paraná, Curitiba PR, Brazil. 
SCAs have a prevalence of around 3 to 4.2 cases per 100,000 people $^{6,7}$.

The ever growing number of SCA subtypes currently reaches up to 30 distinct loci with the most common been types 1, 2, 3 (Machado Joseph disease), 6, and 7. By far, SCA 3 is the most common subtype worldwide, particularly in Portugal, Brazil, Japan and China, but there are some expected geographic variations of prevalence. SCA type 2 has a high incidence in Cuba, and India ${ }^{2-5,8,9}$.

The most common types of SCAs (types 1, 2, 3, 6 and 7) are caused by CAG trinucleotide repeat expansions in the respective genes ${ }^{2-5,8-10}$.

Electronystagmography (ENG) has allowed the possibility of sensitizing the study of the vestibular labyrinth and its links and pathways to the central nervous system (SNC), and has brought about the completion of a topodiagnosis for peripheral and central vestibular loss.

The fundamental element for vestibular analysis is nystagmus, which is a series of ocular movements with fast and slow components in opposite directions, and which occur alternately. The tests which comprise the vestibular exam allow an evaluation of the relationship between balance and posterior vestibular labyrinth function, the vestibular branches of the VIII cranial nerve, the vestibular nuclei in the floor of the IV ventricle, the vestibular pathways and especially, the vestibulo-oculomotor, vestibulocerebellar, vestibulospinal and vestibuloproprioceptive-cervical inter-connections. In central otoneurological syndromes it is observed that manifestations of disorders in the central vestibular system are predominant in the labyrinthic tests ${ }^{11}$.

The objective of this study is to describe the alterations observed in ENG of patients with SCA types 2 and 3.

\section{METHOD}

This study was approved by the Committee of Institutional Ethics, ruling n ${ }^{\circ}$. 058/2008 and all patients gave informed consent.

Sixteen patients (7 female and 9 male) were evaluated in the Movement Disorders Unit, from Neurology Service, Hospital de Clínicas, of Federal University of Paraná, with a final diagnosis of SCA (9 SCA type 3 and 7 SCA type 2), according to molecular genetic techniques with the use of polymerase chain reaction $(\mathrm{PCR})^{10,12,13}$. Their ages ranged between 17 and 54 years (mean, 41.1; standard deviation (SD), 9.5) and the disease duration ranged between 2 and 18 years (mean, 9.7; standard deviation (SD), 3.9.) All patients were evaluated in the Otoneurology Unit of the Tuiuti University of Paraná. Patients with significant visual, psychiatric, rheumatological, and musculoskeletal vulnerabilities or any abnormality that prevented completion of the protocol, were excluded in the study.
The patients were submitted to the following procedures:

Anamnesis - A questionnaire was administered with emphasis on otoneurological signs and symptoms.

Otorhinolaryngological evaluation - Administered with the objective of excluding any other alteration that might interfere with the exam.

Patients undertook a special diet, starting 72 hours before the otoneurological exams (abstaining from the intake of coffee, any kind of soda or caffeinated tea, chocolate, smoke, or alcohol). Analgesics, tranquilizers, antihistaminic and antivertigo medications were suppressed during this period to minimize possible interferences with the test results. Three hours of fasting was recommended prior to the exam.

Vestibular evaluation - Vestibular function evaluation is composed of many labyrinthine function and ocular tests. The first part of our patients evaluation was clinical and consisted of a systematic search for spontaneous, gaze, and positional nystagmus - Brandt and Daroff's maneuver ${ }^{14}$. The second part consisted of interpretation of the ENG test results, which is the objective register of the variations in the corneoretinal potentials, captured by sensitive electrodes. The ENG test is composed of calibration of ocular movements, search for spontaneous and gaze nystagmus, the oscillatory tracking test, optokinetic nystagmus search, and rotatory and caloric tests.

We performed ENG with three-channel equipment (Berger Eletromedicina, model VN316, made in São Paulo, São Paulo, Brazil), rotating chair (Ferrante, model COD 14200, made in São Paulo, São Paulo, Brazil), a visual stimulator (Neurograff Eletromedicina, model EV VEC, São Paulo, São Paulo, Brazil), and an air caloric stimulator (Neurograff Eletromedicina, model NGR 05, São Paulo, São Paulo, Brazil).

We compared results with normal standards, obtained from epidemiological studies for the Brazilian population ${ }^{15-17}$. The criteria used to analyze each test as well as to distinguish central from peripheral vestibulopathy as shown in Table 1.

\section{Statistical method}

The descriptive analysis of the data from the anamnesis and the vestibular evaluation was performed.

\section{RESULTS}

The most reported symptoms in the anamnesis were the prevalence of gait disturbances (93.75\%), dysarthria (43.75\%), headache (43.75\%), dizziness (37.50\%) and dysphagia (37.50\%) as shown in Table 2.

The evaluation of vestibular function, including positional, gaze nystagmus, oscillatory track test, optokinetic 


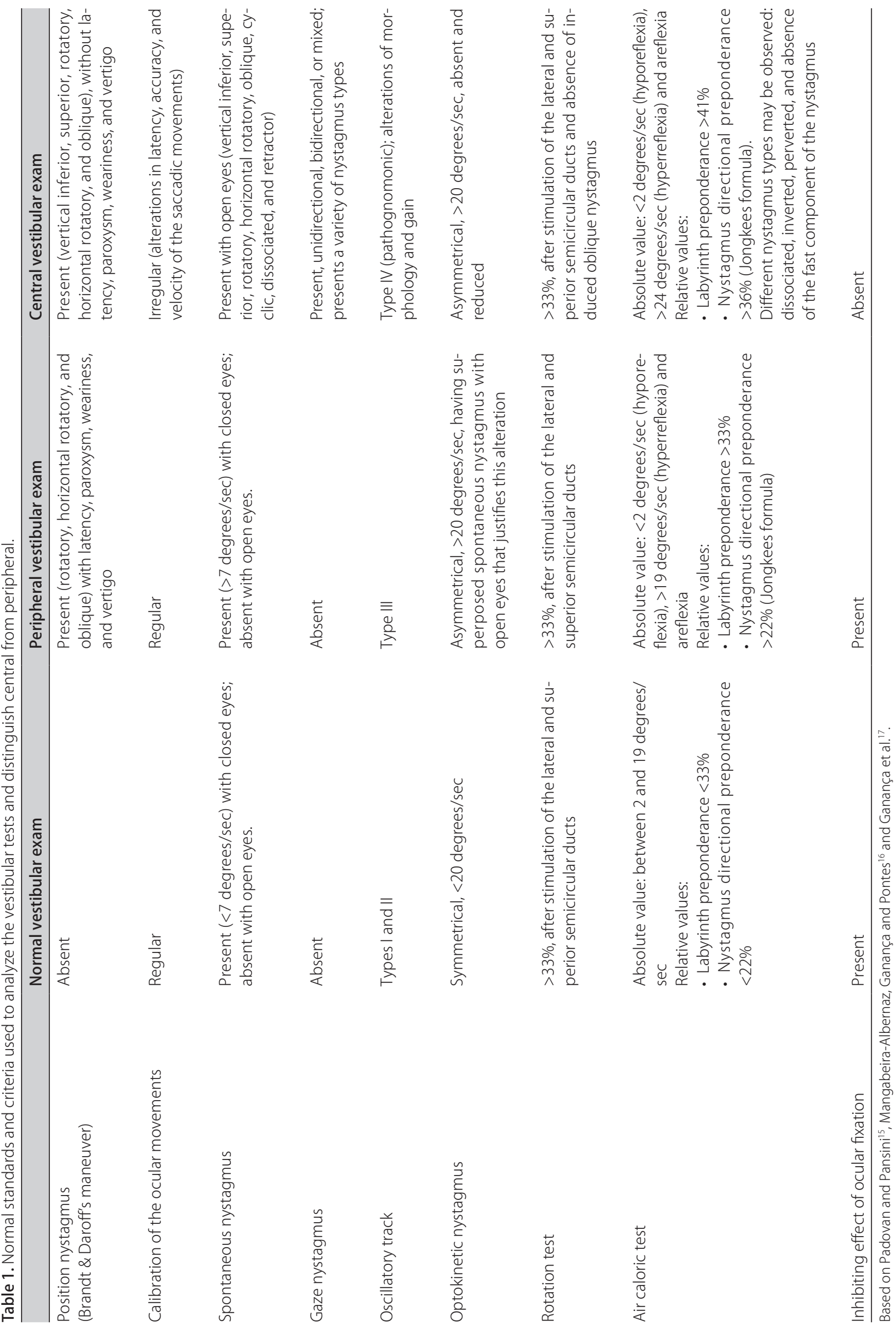


nystagmus, the rotation and caloric tests were abnormal in both SCA groups, as depicted in Table 3.

In the group of altered tests in both SCA, the highest prevalence occurred in the caloric test (75\%), demonstrating labyrinthic hypofunction, and in the rotation test (62.50\%), denoting an absence of reaction in the lateral, anterior and posterior semicircular ducts, as observed in Table 3.

Regarding the result of entrance examination, there was a higher incidence of central vestibular abnormality (68.75\%), as shown in Table 4.

\section{DISCUSSION}

Several studies have studied specific involvement of the vestibular system in SCAs ${ }^{18-21}$.

Oculomotor integration is due to brainstem structures and the combination of vestibular dysfunction with the presence of cerebellar atrophy can contribute significantly to the emergence of instability during walking, which is part of the initial symptoms of $\mathrm{SCA}^{22}$.

Oculomotor phenotypes in differents SCAs were studied by Buttner et al. ${ }^{18}$ described that oculomotor findings are consistent with pure cerebellar involvement in SCA type 6, pontine involvement in SCAs type 1 and 2 and vestibular nerve or nuclei involvement in SCA type 3.

On the other hand, Gordon et al. ${ }^{19}$ published in 2003 a very interesting study evaluating the presence of vestibulo-ocular arreflexia in SCA type 3 patients and the authors concluded that this finding is very suggestive of SCA type 3.
Table 2. Frequency of symptoms of 16 patients with spinocerebellar ataxia.

\begin{tabular}{|c|c|c|}
\hline Symptoms & $\begin{array}{c}\text { Number of } \\
\text { patients }\end{array}$ & $\begin{array}{c}\text { Frequency } \\
(\%)\end{array}$ \\
\hline Gait disturbances & 15 & 93.75 \\
\hline Dysarthria & 7 & 43.75 \\
\hline Headache & 7 & 43.75 \\
\hline Dizziness & 6 & 37.50 \\
\hline Dysphagia & 6 & 37.50 \\
\hline Falls & 5 & 31.25 \\
\hline Diplopia & 5 & 31.25 \\
\hline Hearing loss & 5 & 31.25 \\
\hline Tremor & 4 & 25.00 \\
\hline Voice alteration & 4 & 25.00 \\
\hline Upper and lower limbs paresthesias & 4 & 25.00 \\
\hline Pain, irradiated to shoulder, arm & 3 & 18.75 \\
\hline Pain, difficulty in neck movement & 3 & 18.75 \\
\hline Depression & 3 & 18.75 \\
\hline Blurred vision & 3 & 18.75 \\
\hline Anxiety & 3 & 18.75 \\
\hline Migraine & 3 & 18.75 \\
\hline Tinnitus & 2 & 12.50 \\
\hline Insomnia & 2 & 12.50 \\
\hline Fatigue & 1 & 6.25 \\
\hline
\end{tabular}

Table 3. Frequency of abnormal findings in the vestibular evaluation in 16 patients with spinocerebellar ataxia (SCA).

\begin{tabular}{|c|c|c|c|c|c|c|}
\hline \multirow[b]{2}{*}{ Findings } & \multicolumn{2}{|c|}{ SCA 3} & \multicolumn{2}{|c|}{ SCA2 } & \multicolumn{2}{|c|}{ Total } \\
\hline & $\mathrm{n}$ & $\%$ & $\mathrm{n}$ & $\%$ & $\mathrm{n}$ & $\%$ \\
\hline Bilateral vestibular hyporeflexia & 8 & 88.89 & 4 & 57.14 & 12 & 75.00 \\
\hline Rotative nystagmus absent & 6 & 66.67 & 4 & 57.14 & 10 & 62.50 \\
\hline Gaze nystagmus unidirectional & 1 & 11.11 & 1 & 14.29 & 2 & 12.50 \\
\hline Gaze nystagmus multiple & 2 & 22.22 & - & 0 & 2 & 12.50 \\
\hline Optokinetic nystagmus asymmetrical & 1 & 11.11 & 1 & 14.29 & 2 & 12.50 \\
\hline Gaze nystagmus bidirectional & 1 & 11.11 & - & 0 & 1 & 6.25 \\
\hline Positional vertigo and/or nystagmus & - & 0 & 1 & 14.29 & 1 & 6.25 \\
\hline
\end{tabular}

n: number of patients; \%: frequency.

Table 4. Frequency of results in the vestibular evaluation in 16 patients with spinocerebellar ataxia (SCA).

\begin{tabular}{|c|c|c|c|c|c|c|}
\hline \multirow[b]{2}{*}{ Vestibular exam } & \multicolumn{2}{|c|}{ SCA 3} & \multicolumn{2}{|c|}{ SCA2 } & \multicolumn{2}{|c|}{ Total } \\
\hline & $\mathrm{n}$ & $\%$ & $\mathrm{n}$ & $\%$ & $\mathrm{n}$ & $\%$ \\
\hline Central vestibular disorders & 7 & 77.78 & 4 & 57.14 & 11 & 68.75 \\
\hline Peripheral vestibular disorders & 2 & 22.22 & 1 & 14.29 & 3 & 18.75 \\
\hline Normal vestibular exam & - & 0 & 2 & 28.57 & 2 & 12.50 \\
\hline
\end{tabular}

n: number of patients; \%: frequency. 
In SCA type 6, vertigo and vestibular abnormalities on bedside vestibular examination are common, with forms of nystagmus typical of cerebellar disease, instead labyrinthine disease ${ }^{20}$.

The involvement of the cranial nerves and their nuclei in SCA type 2 were studied by Gierga et al. ${ }^{21}$ using a pathoanatomical analysis in 6 patients who had a clinical diagnosis previously.

Regarding the ENG test, the highest prevalence of vestibular hypofunction was observed in our study in $88.89 \%$ of patients with SCA type 3 and in $57.14 \%$ of patients with SCA type 2. Caloric tests were abnormal in $75 \%$, associated to absence of reaction to the rotation test in $62.50 \%$, and presence of gaze-evoked nystagmus in $31.25 \%$. Central vestibular disorders were detected in the vestibular exam in $77.78 \%$ of patients with SCA type 3 and $57.14 \%$ of patients with SCA type 2, and peripheral vestibular disorders were found in $22.22 \%$ of patients with SCA 3 and $14.29 \%$ of patients with SCA type 2.

Lesions of the cerebellar vermis cause ataxia of the superior limbs, titubeation, dysmetria and tremors of the ocular movements and it is this part that manifests electrical activity during extension of the ocular and neck muscles. Some evidence suggests that lesions of the cerebellar vermis cause vertical dysmetria while more lateral or paravermianas lesions cause horizontal dysmetria. Furthermore, the more anterior the lesion, the more intense the dysmetria in superior vision and the more posterior the lesion, the more intense the dysmetria in inferior vision ${ }^{23}$. The most exhibited alterations in other studies ${ }^{11,24,25}$ were the presence of positional nystagmus, irregular calibration of ocular movements, spontaneous rebound nystagmus, multiple gaze nystagmus, optokinetic abnormality, pendular tracking, vestibular hypofunction and the absence of the inhibitory effect of ocular fixation.

In the group of damaged neuronal structures, vestibular hypofunction is known to occur, but little is known regarding when and why it happens ${ }^{19,24}$. Yoshizawa et al. ${ }^{26}$ evaluated two patients with SCA type 3 after genetic confirmation of the disease and at the onset of symptoms of the disease; that is one year in case 1 and three years in case 2. It was observed that in both cases there was no response to the caloric test. Takegoshi et al. ${ }^{27}$ in other study demonstrated that spinocerebellar degeneration is one of the clinical entities of vestibular system disorders.

Yoshizawa et al..$^{28}$ reported a reduction in the size of the pontine tegmentum revealed in the MRI scan, in patients with SCA type 3, thus demonstrating, that it is in this region where the vestibular nuclei, prepositus nucleus of perihypoglossal nuclei and neurons of the paramedian group which are related to the vestibular system, are all located. The precocious degeneration of these structures may lead to atrophy of the brainstem.

Zeigelboim et al ${ }^{11}$ reported that loss of ciliated cells in the ampullary cupula and the maculae, decline in the number of neurons of the vestibular ganglion (of Scarpa), degeneration of otoliths, decrease in labyrinthic blood flow, progressive depression of neural stability, reduction in the capacity for compensation of the vestibuloocular and vestibulospinal reflexes, all contribute to the decrease in speed of tracking movements and to rotary and caloric hyporeactivity of the central and peripheral vestibular system, which are characteristics present in SCAs types 2 and 3.

SCA type 2 is characterized by cerebellar atrophy with loss of Purkinje and granular cells, olivary neurons, substantia nigra and cells in the anterior horn of the spinal cord ${ }^{2,4,5}$.

Anatomopathologic studies of the vestibular complex and its association of fibre bundles in four patients with SCA type 3, revealed that the five nuclei of the complex (interstitial, lateral, medial, inferior and superior vestibular nuclei) undergo neurodegenerative processes owing to the disease, thus demonstrating that all the associated fibre bundles (ascending tract of Deiters, juxtarestiform body, lateral and medial vestibulospinal tracts, medial longitudinal fascicle, vestibular portion of the VIII cranial nerve) undergo disseminated neuronal loss causing atrophy and demyelination of its structures ${ }^{29}$. These lesions may explain the alterations in the brainstem, postural instability with imbalance, oculomotor deficits (impaired optokinetic nystagmus, slow saccadic eye movements and absent caloric response) and the presence of a pathological vestibulo-ocular reflex ${ }^{18,29}$.

Molecular genetic tests are the most important complementary exam to make the diagnosis of SCAs. On the other hand, clinical approach to SCAs, in general, is very difficult, because, there is a overlapping of clinical manifestations of the different genotypes, so vestibular exams could be an important auxiliary tool to investigate patients with SCAs.

\section{REFERENCES}

1. Teive HAG. Spinocerebellar degenerations in Japan. New insights from an epidemiological study. Neuroepidemiol 2009;32:184-185.

2. Schöls L, Bauer P, Schmidt T, Schulte T, Riess O. Autosomal dominant cerebellar ataxias: clinical features, genetics, and pathogenesis. Lancet Neurol 2004;3:291-304

3. Teive HAG. Spinocerebellar ataxias. Arq Neuropsiquiatr 2009;67:1133-1142.

4. Soong BW, Paulson HL. Spinocerebellar ataxias: an update. Curr Opin Neurol 2007;20:438-446.

5. Klockgether T. Recent advances in degenerative ataxias. Curr Opin Neurol 2000;13:451-455.

6. van de Warrenburg BP. Autosomal dominant cerebellar ataxias in the Netherlands: a national inventory. Ned Tijdschr Geneeskd 2001;145: 962-967.

7. Erichsen AK, Koht J, Stray-Pedersen A, Abdelnoor M, Tallaksen CM. Prev- 
alence of hereditary ataxia and spastic paraplegia in southeast Norway: a population-based study. Brain 2009;132:1577-1588.

8. Jardim LB, Silveira I, Pereira ML, et al. A survey of spinocerebellar ataxia in South Brazil-66 new cases with Machado-Joseph disease, SCA7, SCA8, or unidentified disease-causing mutations. J Neurol 2001;248:870-876.

9. Teive HAG, Roa BB, Raskin S, et al. Clinical phenotype of Brazilian families with spinocerebellar ataxia 10. Neurology 2004;63:1509-1512.

10. Pulst SM. Inherited ataxias: an introduction. In: Pulst SM (Ed). Genetics of movement disorders. Amsterdam: Academic Press, 2003:19-34.

11. Zeigelboim BS, Jurkiewicz AL, Fukuda Y, Mangabeira-Albernaz PL. Vestibular disorders in degenerative diseases of the central nervous system [in Portuguese]. Pró-Fono 2001;13:263-270.

12. Duenas AM, Goold R, Giunti P. Molecular pathogenesis of spinocerebellar ataxias. Brain 2006;129:1357-1370.

13. Pearsons CE, Edamura KN, Cleary JD. Repeat instability: mechanisms of dynamic mutations. Nat Rev Genet 2005;6:729-742.

14. Brandt T, Daroff RB. Physical therapy for benign paroxysmal positioning vertigo. Arch Otolaryngol 1980;106:484-485.

15. Padovan I, Pansini M. New possibilities of analysis in electronystagmography. Acta Otolaryngol 1972;73:121-125.

16. Mangabeira-Albernaz PL, Ganança MM, Pontes PAL. Operational model of the vestibular apparatus. In: PL Mangabeira-Albernaz, MM Ganança (Eds). Vertigo [in Portuguese]. São Paulo: Moderna, 1976:29-36.

17. Ganança CC, Souza JAC, Segatin LA, et al. Normal limits of parameters for evaluation with digital electronystagmography neurograff [in Portuguese]. Acta Awho 2000;19:105.

18. Buttner N, Geschwind D, Jen JC, Perlman S, Pulst SM, Baloh RW. Oculomotor phenotypes in autosomal dominant ataxias. Arch Neurol 1998; 55:1353-1357.
19. Gordon CR, Joffe V, Vainstein G, Gadoth N. Vestibulo-ocular arreflexia in families with spinocerebellar ataxia type 3 (Machado-Joseph disease). J Neurol Neurosurg Psychiatry 2003;74:1403-1406.

20. Yu-Wai-Man P, Gorman G, Bateman DE, Leigh RJ, Chinnery PF. Vertigo and vestibular abnormalities in spinocerebellar ataxia type 6. J Neurol 2009;256:78-82.

21. Gierga K, Bürk K, Bauer M, et al. Involvement of the cranial nerves and their nuclei in spinocerebellar ataxia type 2 (SCA2). Acta Neuropathol 2005; 109:617-631.

22. Nacamagoe $K$, Iwamoto $Y$, Yoshida K. Evidence for brainstem structures participating in oculomotor integration. Science 2000;288:857-859.

23. Cogan DG,Chu FC, Reingold DB. Ocular signs of cerebellar disease. Arch Ophthalmol 1982;100:755-760.

24. Mallinson AL, Longridge NS, Mcleod PM. Machado-Joseph disease: the vestibular presentation. J Otolaryngol 1986;15:184-188.

25. Tsutsumi T, Kitamura K, Tsunoda A, Noguchi Y, Mitsuhashi M. Electronystagmographic findings in patients with cerebral degenerative disease. Acta Otolaryngol 2001;545:136-139.

26. Yoshizawa T, Nakamagoe K, Ueno T, Furusho K, Shoji SI. Early vestibular dysfunction in Machado-Joseph disease detected by caloric test. J Neurol Sci 2004;221:109-111.

27. Takegoshi H, Murofushi T. Vestibular evoked myogenic potentials in patients with spinocerebellar degeneration. Acta Otolaryngol 2000;120:821-824.

28. Yoshizawa T, Watanabe N, Furusho K, Shoji SI. Magnetic resonance imaging demonstrates differential atrophy of pontine base and tegmentum in Machado-Joseph disease. J Neurol Sci 2003;215:45-50.

29. Rüb U, Brunt ER, Del Turco D, et al. Degeneration of the central vestibular system in spinocerebellar ataxia type 3 (SCA3) patients and its possible clinical significance. Neuropathol Applied Neurobiol 2004;30:402-414. 